\title{
Short-term comparative study of three-dimensional and two-dimensional laparoscopic surgery for total extraperitoneal primary inguinal hernia repair
}

\author{
Ah Yoon Kim, Sung II Choi, Jung Hyun Yeom \\ Department of Surgery, Kyung Hee University Hospital at Gangdong, Seoul, Korea
}

Purpose: The aim of this study was to compare the short-term outcomes of two-dimensional (2D) and three-dimensional (3D) laparoscopic surgery for total extraperitoneal (TEP) primary inguinal hernia repair.

Methods: This was a single-center, retrospective, observational database study of 38 patients who underwent laparoscopic TEP inguinal hernia repair from March 1, 2019 to August 30, 2019 at Kyung Hee University Hospital at Gangdong in Seoul, Korea.

Results: There was no significant difference in sex ratio, age, or body mass index between the two groups. The 2D group had two patients with direct hernia and 18 patients with indirect hernia. The 3D group had five patients with direct hernia, 11 patients with indirect hernia, and two patients with femoral hernia. The mean operation time was 38.2 minutes in the $2 \mathrm{D}$ group compared with 37.2 minutes in the $3 \mathrm{D}$ group. There was no severe intraoperative bleeding in either group. During the operation, peritoneal tearing occurred in 12 out of 20 patients in the $2 \mathrm{D}$ group compared with five out of 18 patients in the $3 \mathrm{D}$ group $(p=0.02)$. The average length of hospital stay was 1.3 days in both groups. The numeric rating scale score was 3.3 and 3 in the $2 \mathrm{D}$ group and the $3 \mathrm{D}$ group, respectively. In the $2 \mathrm{D}$ group, two patients revisited the outpatient clinic because of the postoperative occurrence of seroma and varicocele.

Conclusion: A 3D laparoscopic surgery is feasible and safe for inguinal hernia repair and showed less peritoneal tearing compared with 2D laparoscopic surgery for primary inguinal hernia repair.

Keywords: Herniorrhaphy, Laparoscopy, Three-dimensional image, Medical imaging, Image enhancement

This is an Open Access article distributed under the terms of the Creative Commons Attribution Non-Commercial License (http:// creativecommons.org/licenses/by-nc/4.0/) which permits unrestricted non-commercial use, distribution, and reproduction in any medium, provided the original work is properly cited.
Received February 16, 2021

Revised April 21, 2021

Accepted May 23, 2021

Corresponding author

Sung Il Choi

Department of Surgery, Kyung Hee

University Hospital at Gangdong, 892

Dongnam-ro, Gangdong-gu, Seoul

05278, Korea

Tel: +82-2-440-6136

Fax: +82-2-440-8197

E-mail:drchoi@khu.ac.kr ORCID:

https://orcid.org/0000-0002-0662-0951

\section{INTRODUCTION}

With more than 20 million patients undergoing inguinal hernia repair annually, it is one of the most frequently performed surgical procedures worldwide [1]. Over the last two centuries, a number of procedures have been described for the repair of inguinal hernias, starting from Marcy repair and the milestone Bassini repair up to laparoscopic inguinal hernia repair. There are two standardized techniques for laparoscopic inguinal hernia repair; transabdominal preperitoneal (TAPP) repair, which was described by Arregui et al. [2] in 1992, and total extraperitoneal (TEP) repair, as described by McKernan and Laws [3] in 1993.

In the early 1990s, laparoscopic techniques entered the field of general surgery; the first cases of minimally invasive inguinal hernia repair were performed in 1992 [3]. Laparoscopic surgery has revolutionized clinical practice. Over the last decades, technological advances, such as high-definition (HD) cameras, dedicated instruments, and articulating staplers have improved the 
safety and feasibility of laparoscopic procedures [4,5].

Nevertheless, laparoscopic surgery is particularly challenging for beginners. The main challenge is that the three-dimensional (3D) working space is projected two-dimensionally (2D) on a monitor, resulting in the loss of depth perception [6]. The greatest contribution of $3 \mathrm{D}$ imaging to surgical practice is the introduction of depth perception. Depth perception allows us to carry out our actions with fewer mistakes while both navigating and performing procedures [7]. The 3D view allows performance of advanced techniques in particular conditions, such as in small and deep spaces, and promotes complex surgical laparoscopic procedures, such as suturing and intracorporeal knotting [4].

The aim of this study was to compare the short-term outcomes of 2D and 3D laparoscopic surgeries for TEP primary inguinal hernia repair. In addition, we report our experience with laparoscopic hernia surgery using a 3D HD vision system.

\section{MATERIALS AND METHODS}

This was a single-center, retrospective, observational database study of 38 patients who underwent laparoscopic TEP inguinal hernia repair from March 1 to August 30, 2019, at Kyung Hee University Hospital at Gangdong in Seoul, Korea. Of the 38 patients, 20 underwent 2D laparoscopic surgery (referred to as the $2 \mathrm{D}$ group) and 18 underwent 3D laparoscopic surgery (referred to as the $3 \mathrm{D}$ group). All surgeries were performed by a single experienced surgeon. The 2D laparoscopic surgery was performed using the Olympus laparoscopic system 2014 version (Olympus, Tokyo, Japan), and 3D laparoscopic surgery was performed using the Olympus laparoscopic system 2018 version. The two groups were assigned on the basis of the availability of the operation system in the schedule.

\section{Surgical procedure}

The surgeon and assistant stood on the side opposite to the hernia being repaired. A 1-cm-long transumbilical incision was made, and the TEP procedure was performed by inserting a 10$\mathrm{mm}$ and two 5-mm trocars. Once in position, the trocars were inflated with air under direct vision using a $10-\mathrm{mm} 0^{\circ}$ telescope. During 3D laparoscopic surgery, the surgeon wore 3D glasses. Then, the camera was introduced through the infraumbilical optic port, and the space was expanded by blunt dissection with the $0^{\circ}$ telescope. Two 5-mm working ports were inserted below the umbilicus; the inferior one was inserted at least 4 to $5 \mathrm{~cm}$ away from the pubic symphysis in the midline, and the other was inserted midway between the first port and the umbilicus. Then, the camera view was changed from a $0^{\circ}$ to $30^{\circ}$ telescope. Extension into the extraperitoneal space was performed by dissection using electrocautery and was directed toward the anterior supe- rior iliac spine. During this process, the epigastric vessels were identified and preserved, and superior attachment to the rectus abdominis muscle was maintained. Dissection was continued by gentle traction on the cord elements in order to identify and free the peritoneal sac from the spermatic cord, vas deferens, and spermatic vessels. The subsequent step includes exposing the posterior aspect of the pubic bone, using sharp and blunt dissection, which represents the most distal dissection plane where the inferomedial aspect of the prosthetic 3D mesh will sit. The 3D mesh was not fixed by either stapling or suturing. The preperitoneal space was deflated under direct vision, ensuring that the reduced peritoneum and fatty tissues remained above the prosthetic material.

Intraoperative bleeding, which was used as a point of comparison, refers to major bleeding due to injury to epigastric vessel injury during the surgery. The patient's pain score was measured using the numeric rating scale (NRS) on the morning of postoperative day 1. Patients with incarcerated hernias were excluded from the study.

\section{Statistical analysis}

The data were analyzed using IBM SPSS version 20.0 (IBM Corp., Armonk, NY, USA) and SAS version 9.4 (SAS Institute, Cary, NC, USA). Age, operation duration, length of hospital stay, and pain score were expressed as means and ranges. An independent $t$ test was performed to analyze age, body mass index (BMI), operation time, and pain score. The chi-square test and Fisher exact test were performed to compare sex, hernia type, number of hernias, peritoneal tearing during operation, and outpatient department (OPD) visit. Statistical significance was set at $p<0.05$.

\section{RESULTS}

Patient characteristics and hernia types are shown in Table 1. The male-to-female sex ratio in the 2D group was 19:1. In the $3 \mathrm{D}$ group, there were 14 males and four females. There was no

Table 1. Patient characteristics

\begin{tabular}{lccc}
\multicolumn{1}{c}{ Characteristic } & $\begin{array}{c}\text { 2D group } \\
(\mathrm{n}=20)\end{array}$ & $\begin{array}{c}\text { 3D group } \\
(\mathrm{n}=18)\end{array}$ & p value \\
\hline Sex, male:female & $19: 1$ & $14: 4$ & 0.17 \\
Age $(\mathrm{yr})$ & $57.1(22-83)$ & $60.1(31-84)$ & 0.27 \\
$\begin{array}{l}\text { Hernia type, } \\
\text { direct/indirect/femoral }\end{array}$ & $2 / 18 / 0$ & $5 / 11 / 2$ & \\
Body mass index $\left(\mathrm{kg} / \mathrm{m}^{2}\right)$ & $23.8(16.0-28.6)$ & $24.5(17.6-30.4)$ & 0.42 \\
\hline
\end{tabular}

Values are presented as number only or mean (range).

2D, two-dimensional; 3D, three-dimensional. 
significant difference in sex ratio between the two groups. The age distribution of the $2 \mathrm{D}$ group was 22 to 83 years, with a mean of 57.1 years. The age distribution of the 3D group was 31 to 84 years, with a mean of 60.1 years. There was no significant difference in age distribution between the two groups. The 2D group included two patients with direct hernia and 18 patients with indirect hernia. In the $3 \mathrm{D}$ group, there were five patients with direct hernia, 11 with indirect hernia, and two with femoral hernia. The BMI was $23.8 \mathrm{~kg} / \mathrm{m}^{2}$ and $24.5 \mathrm{~kg} / \mathrm{m}^{2}$ in the $2 \mathrm{D}$ and $3 \mathrm{D}$ groups, respectively.

The results of these operations are summarized in Table 2. The mean \pm standard deviation of operation time was $38.2 \pm$ 10.86 minutes in the $2 \mathrm{D}$ groups and $37.2 \pm 13.74$ minutes in the $3 \mathrm{D}$ groups, respectively. There was no intraoperative bleeding in either group. Intraoperative peritoneal tearing occurred in 12 patients in the $2 \mathrm{D}$ group compared to five patients in the $3 \mathrm{D}$ group $(p=0.02)$. The average length of hospital stay did not differ between the two groups; however, a patient in the 3D group was hospitalized for 1 additional day due to difficulty in voiding. The mean NRS scores were 3.3 and 3 in the 2D and 3D groups, respectively $(p=0.96)$. Patients visited the OPD approximately 1 week after discharge for their follow-up. There were no abnormal findings in the $3 \mathrm{D}$ group at the outpatient visit. However, in the
$2 \mathrm{D}$ group, two patients revisited the OPD because of the postoperative occurrence of seroma and varicocele.

Tables 3 and 4 present the results of the normality test. Table 3 shows a comparison of the categorical data of 3D and 2D laparoscopic surgeries. Sex, hernia type, number of hernias, and number of OPD visits were analyzed using Fisher exact test. The ratio of sex, hernia type, hernia number, and OPD visits in the two

Table 2. Operation results

\begin{tabular}{lccc}
\hline \multicolumn{1}{c}{ Variable } & $\begin{array}{c}\text { 2D group } \\
(\mathrm{n}=20)\end{array}$ & $\begin{array}{c}\text { 3D group } \\
(\mathrm{n}=18)\end{array}$ & p value \\
\hline Operation time (min) & $38.3(21-65)$ & $37.2(25-60)$ & 0.73 \\
\hline $\begin{array}{l}\text { Intraoperative bleeding } \\
\text { Peritoneal tearing } \\
\text { during operation }\end{array}$ & 0 & 0 & \\
Hospital stay (day) & 12 & 5 & 0.02 \\
Pain score, NRS & $3.3(1-2)$ & $1.3(1-3)$ & 0.42 \\
OPD revisit & 2 & $3(0-5)$ & 0.96 \\
\hline
\end{tabular}

Values are presented as number only or mean (range).

2D, two-dimensional; 3D, three-dimensional; NRS, numeric rating scale; OPD, outpatient department.

Table 3. Comparison of categorical data from the 3D and 2D laparoscopic surgeries

\begin{tabular}{|c|c|c|c|c|}
\hline Variable & Total patients $(n=38)$ & $2 \mathrm{D}$ group $(\mathrm{n}=20)$ & $3 D$ group $(n=18)$ & $p$ value \\
\hline \multicolumn{5}{|l|}{ Sex (yr) } \\
\hline Female & 5 & $1(5.0)$ & $4(22.2)$ & \multirow[t]{2}{*}{$0.3867^{b}$} \\
\hline Male & 33 & $19(95.0)$ & $14(77.8)$ & \\
\hline \multicolumn{5}{|l|}{ Hernia type } \\
\hline Direct & 7 & $2(10.0)$ & $5(27.8)$ & \multirow[t]{4}{*}{$0.0804^{b}$} \\
\hline Indirect & 29 & $16(80.0)$ & $11(61.1)$ & \\
\hline Femoral & 2 & $0(0)$ & $2(11.1)$ & \\
\hline Pantaloon & 2 & $2(10.0)$ & $0(0)$ & \\
\hline \multicolumn{5}{|l|}{ No. of hernias } \\
\hline Unilateral & 38 & $20(100)$ & $17(94.4)$ & \multirow[t]{2}{*}{$0.0735^{b)}$} \\
\hline Bilateral & 1 & $0(0)$ & $1(5.6)$ & \\
\hline \multicolumn{5}{|c|}{ Peritoneal tearing during operation } \\
\hline Yes & 17 & $12(60.0)$ & $5(27.8)$ & \multirow[t]{2}{*}{$0.0105^{a)}$} \\
\hline No & 21 & $8(40.0)$ & $13(72.2)$ & \\
\hline \multicolumn{5}{|l|}{ No. of OPD visits } \\
\hline 1 & 35 & $18(90.0)$ & $17(94.4)$ & \multirow[t]{2}{*}{$>0.9999^{b)}$} \\
\hline 2 & 3 & $2(10.0)$ & $1(5.6)$ & \\
\hline
\end{tabular}

Values are presented as number only or number (\%).

2D, two-dimensional; 3D, three-dimensional; OPD, outpatient department.

Analyzed by ${ }^{\text {a) }}$ chi-square test, ${ }^{\text {b) }}$ Fisher exact test. 
Table 4. Comparison of continuous data from the 3D and 2D laparoscopic surgeries

\begin{tabular}{lcccccc}
\hline \multirow{2}{*}{ Variable } & \multicolumn{2}{c}{ 2D group } & \multicolumn{2}{c}{ 3D group } & \multirow{2}{*}{ p value ${ }^{\text {a) }}$} \\
\cline { 2 - 3 } & No. & Mean \pm SD & No. & Mean \pm SD & \\
\hline Age $(\mathrm{yr})$ & 20 & $60.1 \pm 17.90$ & 18 & $57.1 \pm 17.67$ & 0.6057 \\
Body mass index $\left(\mathrm{kg} / \mathrm{m}^{2}\right)$ & 20 & $23.4 \pm 2.79$ & 18 & $24.5 \pm 3.23$ & 0.2604 \\
Operation time $(\mathrm{min})$ & 20 & $35.5 \pm 10.86$ & 18 & $38.2 \pm 13.74$ & 0.5052 \\
Pain score & 20 & $3.1 \pm 1.60$ & 18 & $3.0 \pm 1.14$ & 0.6758 \\
\hline
\end{tabular}

2D, two-dimensional; 3D, three-dimensional; SD, standard deviation.

${ }^{\text {a) }}$ Analyzed by independent $t$ test.

groups showed a difference, but not all variables were statistically significant. Only peritoneal tearing during the operation was analyzed using the chi-square test. The $p$ value was 0.01 , indicating statistically significant results. Table 4 shows a comparison of 3D and 2D laparoscopic surgeries for continuous data. Age, BMI, operation time, and pain score were analyzed using an independent $t$ test. None of the variables in the $2 \mathrm{D}$ and $3 \mathrm{D}$ groups showed statistically significant differences.

\section{DISCUSSION}

Although there is little doubt that minimally invasive surgery, particularly laparoscopic surgery, benefits patients, surgeons require a lot of training to get used to a $2 \mathrm{D}$ laparoscope. Laparoscopic surgery is more challenging than open surgery partly because surgeons need to operate in a 3D space according to a $2 \mathrm{D}$ projection on a monitor, which results in the loss of depth perception [8]. The 3D laparoscopy has taken laparoscopic surgery to a new level, offering the surgeon stereoscopic vision, which is valuable for difficult activities such as suturing and knotting, which demand a high degree of spatial perception. Numerous recent studies have shown that 3D laparoscopic surgery can reduce the operation time, intraoperative blood loss, and surgeon's learning curve compared with 2D laparoscopic surgery [9-12]. Although 3D vision technology has substantially improved in recent years and various technical concepts have been implemented, it is still not the accepted standard for laparoscopic abdominal surgery. A key reason for this is that $3 \mathrm{D}$ laparoscopy is significantly more expensive than 2D laparoscopy [13]. Moreover, surgeons often complain about the poor quality of the 3D image and the discomfort of wearing 3D glasses [14-16]. In recent years, the development of 3D HD vision systems with better image quality and lower cost has made great progress in $3 \mathrm{D}$ vision technology [17]. Therefore, 3D laparoscopic surgery is currently performed more frequently than before, and research on its effectiveness has also been conducted as the field of application has increased. Previously, comparative studies of 2D and 3D laparoscopic surgeries were conducted in the field of gastrointestinal surgery, obstetrics and gynecology, and urology; therefore, it is important to confirm the safety and effectiveness of the inguinal hernia repair in this study [18-20].

The learning curve of laparoscopic inguinal hernia repair is higher than that of other surgeries because of the ambiguity of the inguinal anatomy. Therefore, peritoneal tearing is frequent in laparoscopic inguinal hernia repair. The reported incidence of peritoneal tears is $10 \%$ to $64 \%$ during TEP [21]. Peritoneal tearing is the most common reason for the conversion of endoscopic extraperitoneal inguinal hernioplasty to TAPP or open approaches [22]. Peritoneal tearing not only leads to the loss of extraperitoneal space but also increases the risk of small bowel adhesions and internal herniation. Furthermore, as the mesh is no longer securely buttressed between the abdominal wall and peritoneum by intraabdominal pressure, it becomes susceptible to migration, particularly when a nonstapling technique is adopted [23]. It is important to note that 3D laparoscopic surgery can reduce the risk of peritoneal tear.

In conclusion, 3D laparoscopic surgery for inguinal hernia patients was observed to be feasible and safe and showed less peritoneal tearing than the $2 \mathrm{D}$ laparoscopic surgery group.

One of the limitations of our study was that it included surgeries performed by a single experienced surgeon. The 3D laparoscopy is superior to 2D laparoscopy in terms of depth perception, so it can reduce the learning curve of beginners. In the case of a novice surgeon, the difference between the two groups could have been more dramatic. If further research compares the outcomes of 2D and 3D laparoscopic surgeries performed by novice surgeons, we believe the excellence of 3D laparoscopy can be better demonstrated.

Another limitation of this study is that it was conducted in a single institution, and the number of study subjects was small. Hence, generalization and confirmation of these findings are limited. Therefore, multicenter studies involving a larger number of subjects are required to improve the reliability of our results.

Additionally, this was a retrospective study that was performed by reviewing the charts. Therefore, it was impossible to analyze the factors that might influence the outcome. In addi- 
tion, it was not possible to conduct preliminary investigations into the factors that could influence the results.

Although the 2D and 3D laparoscopic surgeries showed no statistical difference in operation time, intraoperative bleeding, hospital stay, pain score, and OPD revisit, the 3D laparoscopic surgery showed less peritoneal tearing during the TEP procedure for inguinal hernia repair. Therefore, we conclude that the 3D laparoscopic TEP procedure is feasible and safe for inguinal hernia repair.

\section{NOTES}

\section{Ethical statements}

The study protocol was reviewed and approved by the Institutional Review Board of Kyung Hee University Hospital at Gangdong (No. KHNMC 2021-02-049). The requirement for informed consent was waived because of the retrospective nature of the study.

\section{Authors' contributions}

Conceptualization: All authors

Data curation, Investigation: AYK

Formal analysis: JHY

Funding acquisition: SIC

Methodology, Visualization: AYK, JHY

Project administration: SIC, JHY

Writing-original draft: AYK, SIC

Writing-review \& editing: All authors

All authors read and approved the final manuscript.

\section{Conflict of interest}

All authors have no conflicts of interest to declare.

\section{ORCID}

Ah Yoon Kim, https://orcid.org/0000-0003-4989-1636

Sung Il Choi, https://orcid.org/0000-0002-0662-0951

Jung Hyun Yeom, https://orcid.org/0000-0001-5368-0191

\section{REFERENCES}

1. Merola G, Cavallaro G, Iorio O, et al. Learning curve in open inguinal hernia repair: a quality improvement multicentre study about Lichtenstein technique. Hernia 2020;24:651-659.

2. Arregui ME, Davis CJ, Yucel O, Nagan RF. Laparoscopic mesh repair of inguinal hernia using a preperitoneal approach: a preliminary report. Surg Laparosc Endosc 1992;2:53-58.
3. McKernan JB, Laws HL. Laparoscopic repair of inguinal hernias using a totally extraperitoneal prosthetic approach. Surg Endosc 1993;7:26-28.

4. Agrusa A, Di Buono G, Buscemi S, Cucinella G, Romano G, Gulotta G. 3D laparoscopic surgery: a prospective clinical trial. Oncotarget 2018;9:17325-17333.

5. Vărcuş F, Duţă C, Dobrescu A, Lazăr F, Papurica M, Tarta C. Laparoscopic repair of inguinal hernia TEP versus TAPP. Chirurgia (Bucur) 2016;111:308-312.

6. Patrzyk M, Klee M, Stefaniak T, Heidecke CD, Beyer K. Randomized study of the influence of two-dimensional versus three-dimensional imaging using a novel 3D head-mounted display (HMS-3000MT) on performance of laparoscopic inguinal hernia repair. Surg Endosc 2018;32:4624-4631.

7. Usta TA, Ozkaynak A, Kovalak E, Ergul E, Naki MM, Kaya E. An assessment of the new generation three-dimensional high definition laparoscopic vision system on surgical skills: a randomized prospective study. Surg Endosc 2015;29:2305-2313.

8. Nicolau S, Soler L, Mutter D, Marescaux J. Augmented reality in laparoscopic surgical oncology. Surg Oncol 2011;20:189-201.

9. Lu J, Zheng CH, Zheng HL, et al. Randomized, controlled trial comparing clinical outcomes of 3D and 2D laparoscopic surgery for gastric cancer: an interim report. Surg Endosc 2017;31:2939-2945.

10. Aykan S, Singhal P, Nguyen DP, et al. Perioperative, pathologic, and early continence outcomes comparing three-dimensional and twodimensional display systems for laparoscopic radical prostatectomy-a retrospective, single-surgeon study. J Endourol 2014;28:539-543.

11. Blavier A, Gaudissart Q, Cadière GB, Nyssen AS. Comparison of learning curves and skill transfer between classical and robotic laparoscopy according to the viewing conditions: implications for training. Am J Surg 2007;194:115-121.

12. Chiu CJ, Lobo Prabhu K, Tan-Tam CC, Panton ON, Meneghetti A. Using three-dimensional laparoscopy as a novel training tool for novice trainees compared with two-dimensional laparoscopy. Am J Surg 2015;209:824-827.

13. Hanani M, Cernat V, Beyer K, et al. Comparison of a 3D headmounted display (HMS-3000MT) and 3D passive polarizing display with $2 \mathrm{D}$ technique for first laparoscopic inguinal hernia repair by novice surgeons. Hernia 2020;24:661-668.

14. Wang T, Zheng B. 3D presentation in surgery: a review of technology and adverse effects. J Robot Surg 2019;13:363-370.

15. Taffinder N, Smith SG, Huber J, Russell RC, Darzi A. The effect of a second- generation 3D endoscope on the laparoscopic precision of novices and experienced surgeons. Surg Endosc 1999;13:1087-1092.

16. Shah J, Buckley D, Frisby J, Darzi A. Depth cue reliance in surgeons and medical students. Surg Endosc 2003;17:1472-1474.

17. Mashiach R, Mezhybovsky V, Nevler A, Gutman M, Ziv A, Khaikin M. Three-dimensional imaging improves surgical skill performance in a laparoscopic test model for both experienced and novice laparoscopic surgeons. Surg Endosc 2014;28:3489-3493. 
18. Zhao B, Lv W, Mei D, et al. Comparison of short-term surgical outcome between 3D and 2D laparoscopy surgery for gastrointestinal cancer: a systematic review and meta-analysis. Langenbecks Arch Surg 2020;405:1-12.

19. Yazawa H, Takiguchi K, Imaizumi K, Wada M, Ito F. Surgical outcomes of total laparoscopic hysterectomy with 2-dimensional versus 3-dimensional laparoscopic surgical systems. Fukushima J Med Sci 2018;64:38-45.

20. Dirie NI, Wang Q, Wang S. Two-dimensional versus three-dimensional laparoscopic systems in urology: a systematic review and meta- analysis. J Endourol 2018;32:781-790.

21. Mathew KG, Pokhrel G. Closing peritoneal tear during laparoscopic inguinal hernia repair: simple and effective technique. Hernia 2020;24:1121-1124.

22. Felix EL, Harbertson N, Vartanian S. Laparoscopic hernioplasty: significant complications. Surg Endosc 1999;13:328-331.

23. Lau H, Patil NG, Yuen WK, Lee F. Management of peritoneal tear during endoscopic extraperitoneal inguinal hernioplasty. Surg Endosc 2002;16:1474-1477. 